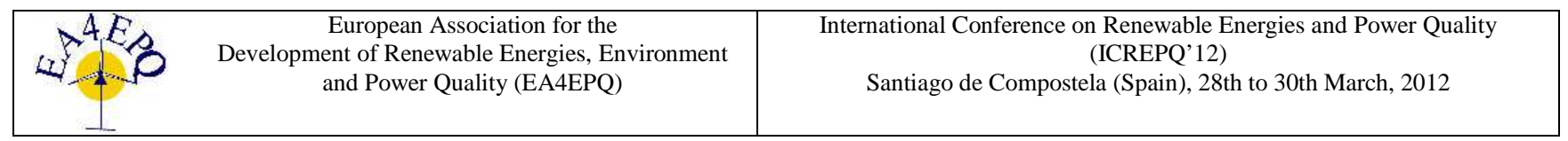

\title{
Experimental study of thermal and vibrational behaviour of an induction motor
}

\author{
D. García ${ }^{1}$, F. T. Oliveira ${ }^{2,3}$, G. Peláez ${ }^{4}$, M.P. Donsión ${ }^{1}$ \\ ${ }^{1}$ Department of Electrical Engineering. University of Vigo. Spain. E-mail: garciavillares@ @otmail.com, donsion@uvigo.es \\ ${ }^{2}$ Department of Electrical Engineering. School of Technology and Management. Polytechnic Institute of Leiria. Portugal. \\ E-mail: ftadeu@yahoo.com \\ ${ }^{3}$ Institute for Systems and Computer Engineering at Coimbra. Portugal \\ ${ }^{4}$ Department of Mechanical Engineering. University of Vigo. Spain
}

\begin{abstract}
Induction machines are the most common option to generate rotary motor in industry, and at present the use of variable speed drives with these machines is spreading in an unprecedented way. This has mostly to do with the advantages provided by these devices, such as added versatility and, in most cases, improved overall efficiency. Because variable speed drives provide a modified wave form, non-sinusoidal, several power quality issues and some effects can be observed. This paper focus particularly on the thermal and vibrational effects, and forms part of a broader study on the effects of the power supply on the behaviour of dynamic rotary loads.
\end{abstract}

\section{Key words}

Induction machines, variable speed drives, thermal analysis, thermography, mechanical vibrations

\section{Introduction}

Nowadays, as in the past, induction machines are designed and their parameters calculated with reference to a rated voltage, assumed to be sinusoidal. However, some of the electrical and mechanical parameters of the induction machine can show considerable differences if a modulated voltage waveform is applied instead, as is the case when variable speed drives (VSD) are used. As an example, figure 1 depicts the voltage and current waveforms at the output of a VSD driving a mechanical load.

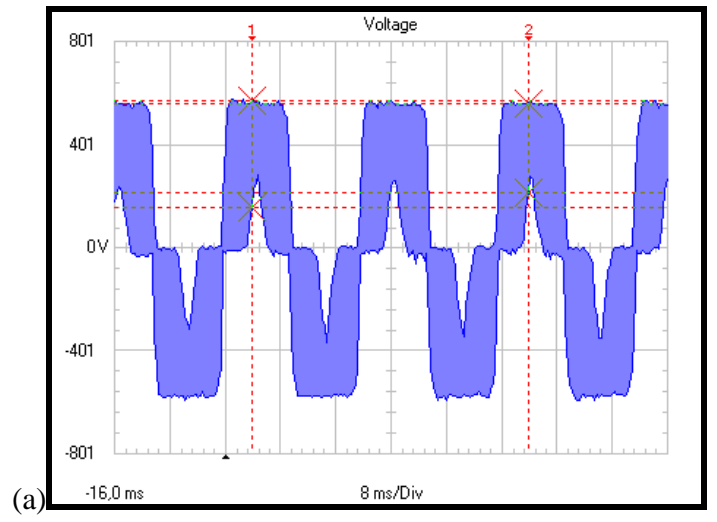

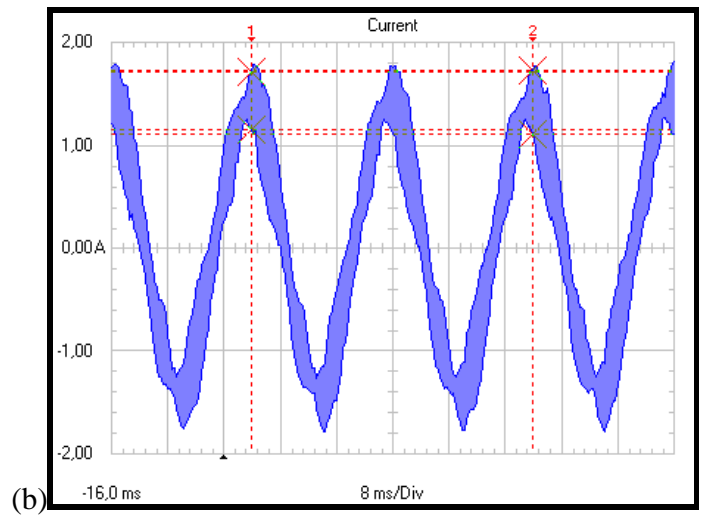

Fig. 1: a) Voltage waveform at the output of a VSD b) Current waveform.

Other system characteristics can also have an influence on the overall behaviour of the system, such as the mechanical characteristics of the load. For instance, a small mass unbalance (similar to what occurs in the wheel of a car) in a rotational shaft may introduce added mechanical vibration (since mechanical vibration is intrinsic to rotary motion), which can be severe if resonance occurs between the vibration natural frequency and one of the power supply waveform harmonic frequencies (considering the Fourier transform of such waveform).

Also, due to the way the magnetic circuit of an induction machine is designed and calculated, the mechanical response to the higher input frequencies is increasingly lower, tending to rest in the saturation part of the hysteresis curve, meaning a considerable amount of the electromagnetic energy supplied to the induction machine, not being converted to rotary motion, is dissipated as heat and noise.

Bearing the former in mind, the need arises to return to the study of the behaviour of the induction machine under these circumstances, starting, as is here presented, with an experimental study of these characteristics. 
The methods and results presented in the latter sections of this paper were obtained through 'classical' laboratory experiments, while at the same time using innovative measuring techniques, such as thermography, to obtain the relevant data.

\section{Experimental equipment and trials}

In order to accomplish the objectives proposed, a trial platform was especially designed and built, so as to accommodate the necessary characteristics and to ensure both precision and comparability of results. Figure 2 shows a tridimensional schematic and a photo of this platform.

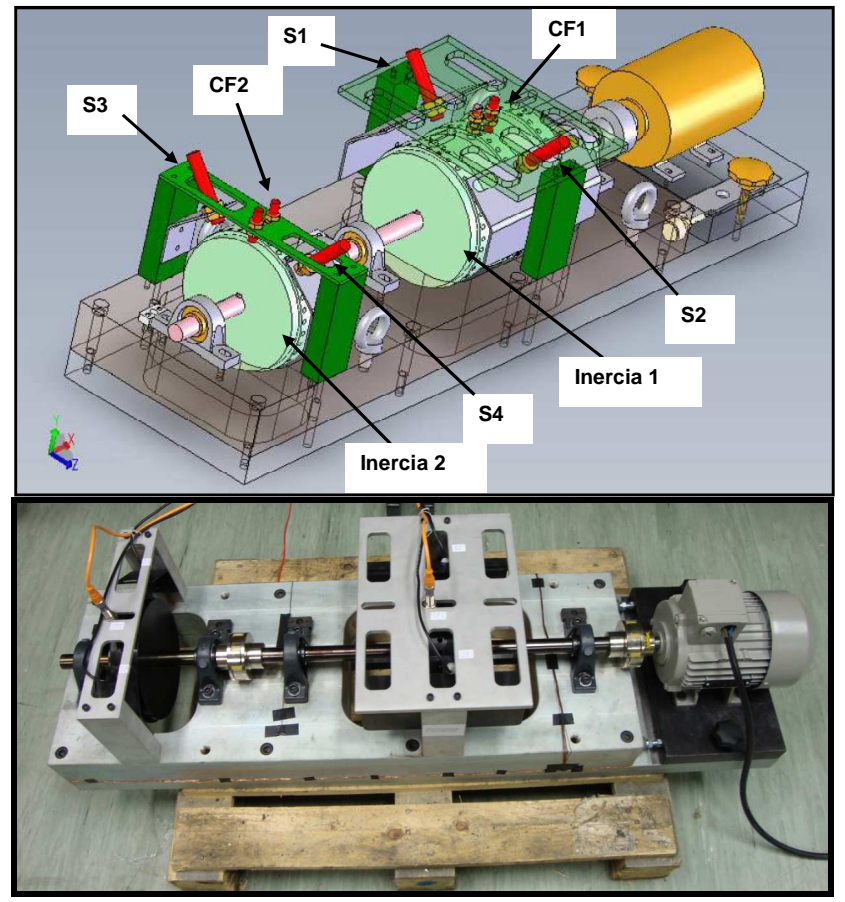

Fig. 2. Schematic and photo of the platform.

The platform built comprises a docking tray, allowing an interchangeable induction machine to be connected, a mechanical shaft where one or two inertias (steel cylinders) can be fitted, and several proximity sensors, accelerometers and other sensors. Table I comprises the detailed information on the characteristics of this platform:

\begin{tabular}{|c|c|}
\hline Trial platform parameters & Value \\
\hline Young's modulus $(\mathrm{E})$ & $210000 \mathrm{MPa}$ \\
\hline Axis diameter $(\mathrm{d})$ & $0.03 \mathrm{~m}$ \\
\hline Axis length $(\mathrm{l})$ & $0.5 \mathrm{~m}$ \\
\hline Axis moment of inertia $(\mathrm{Iz})$ & $\left(\pi \mathrm{d}^{4} / 64\right) 3.976 \cdot 10^{-8} \mathrm{~m}^{4}$ \\
\hline Mass of each disk $(\mathrm{m})$ & $9 \mathrm{~kg}$ \\
\hline
\end{tabular}

Table I. - Trial platform parameters

To ensure comparability of results, as well as attempting to determine the main factors affecting the quantities to be measured and analysed, two induction machines were used, with different efficiency levels. Also, trials were performed connecting the motors directly to the grid, and also using a variable speed drive. For each combination of the former, one and two inertias loads were tested. Table II presents the main parameters of the induction motors used:

\begin{tabular}{|c|c|c|}
\hline & Motor 1 & Motor 2 \\
\hline Number of poles & 2 & 2 \\
\hline Rated voltage (V) & 230 & 230 \\
\hline Rated current (A) & $3.05 / 1.75$ & $2.95 / 1.71$ \\
\hline Rated speed (rpm) & 2855 & 2885 \\
\hline Rated power factor & 0.82 & 0.86 \\
\hline Efficiency at rated power & $\begin{array}{c}\text { IE1 (EFF2) } \\
\text { 72.1\% }\end{array}$ & $\begin{array}{c}\text { IE2 (EFF1) } \\
77.4 \%\end{array}$ \\
\hline
\end{tabular}

Table II. - Induction machines parameters

The temperature of the various points of the platform will be determined using a Flir Thermacam infrared thermographic camera. Mechanical vibration will be measured and calculated from proximity sensors connected to a high performance data acquisition card, connected to a PC.

\section{Thermal analysis}

In order to perform an adequate study of the thermal response, the experimental conditions had to be set regarding the necessary time to achieve thermal equilibrium between the shaft and the surround environment. After some tests, a period of 45 minutes was set to operate the trial (temperature stabilizes before this point), and four or more hours between trials for the platform to return to room temperature. Thermography shots were taken from a fixed stand, due to how thermography results can be affected by distance, other lighting and many other parameters. A thermography image obtained during the trials is shown in figure 3.

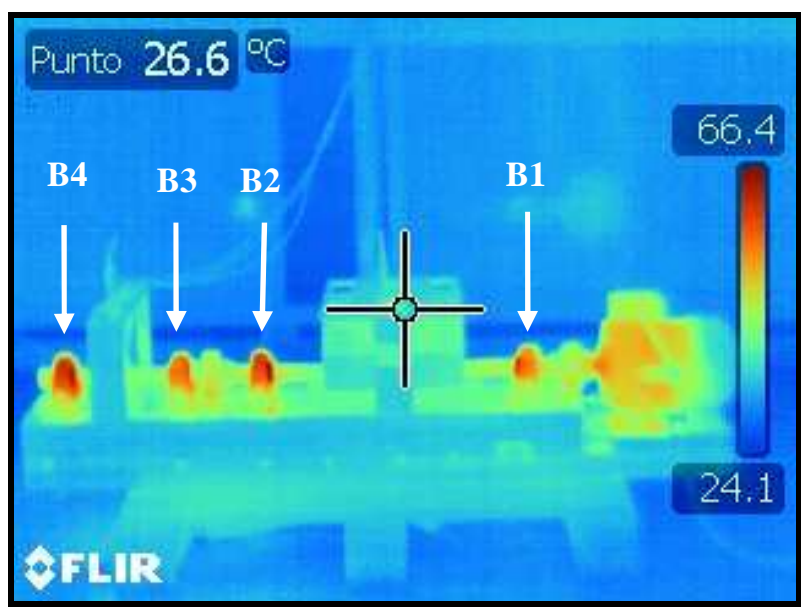

Fig. 3. Thermography image of the platform after 45 minutes: two inertias, motor 1 directly connected to the grid.

As expected, the points where higher temperature ('hot points') are the shaft, the bearings and the motor itself. 
Clearly, temperature increases from right to left, that is, increases as the distance to the motor increases, with the exception of bearing B3 that, because of its proximity with $\mathrm{B} 2$, withstands less friction and thus less heating.

The temperatures of the main points of the platform, obtained throughout the trials, are summarized in table II:

\begin{tabular}{|c|c|c|c|c|c|c|c|}
\hline & \multicolumn{5}{|c|}{ Temperature after 45 minutes $\left({ }^{\circ} \mathrm{C}\right)$} \\
\hline & & & $\begin{array}{c}\text { Bearing } \\
\text { B1 }\end{array}$ & \begin{tabular}{|c} 
Bearing \\
B2 \\
\end{tabular} & $\begin{array}{c}\text { Bearing } \\
\text { B3 } \\
\end{array}$ & $\begin{array}{c}\text { Bearing } \\
\text { B4 } \\
\end{array}$ & Motor \\
\hline \multirow{4}{*}{$\begin{array}{l}\text { Standard } \\
\text { efficiency } \\
\text { (IE1, } \\
\text { EFF2) }\end{array}$} & \multirow{2}{*}{$\begin{array}{c}1 \\
\text { Inertia }\end{array}$} & VSD & 42,2 & 45,8 & - & - & 37,6 \\
\hline & & Grid & 41,8 & 45,4 & - & - & 36,8 \\
\hline & \multirow{2}{*}{$\begin{array}{c}2 \\
\text { Inertias }\end{array}$} & VSD & 38,4 & 52,8 & 41,4 & 54,6 & 38,3 \\
\hline & & Grid & 38,4 & 52,2 & 42,2 & 53,8 & 38,1 \\
\hline \multirow{4}{*}{$\begin{array}{c}\text { High } \\
\text { efficiency } \\
\text { (IE2, } \\
\text { EFF1) }\end{array}$} & \multirow{2}{*}{$\begin{array}{c}1 \\
\text { Inertia }\end{array}$} & VSD & 41,8 & 46,1 & - & - & 35,8 \\
\hline & & Grid & 41,2 & 44,6 & - & - & 34,8 \\
\hline & \multirow{2}{*}{$\begin{array}{c}2 \\
\text { Inertias }\end{array}$} & VSD & 37,8 & 48,8 & 42,2 & 54,2 & 34,9 \\
\hline & & Grid & 38,4 & 48,2 & 41,4 & 53,8 & 35,2 \\
\hline
\end{tabular}

Table II. - A summary of temperatures of the platform elements after each 45-minute trial

A careful look at the table shows that no absolute conclusions can be drawn, although some curious effects can be observed. Temperature is always lower on the nearest bearing of the pair for each mass disk, and higher on the furthest (i.e., lower in B1 than in B2, and in B3 than B4).

Also, considering only the standard efficiency motor, temperatures for direct grid connection are in all cases lower, than the corresponding using the variable speed drive, both for the motor and the bearings.

It is also visible that the introduction of the second inertia lowers the temperature in the nearest bearing, and increases it in the furthest, in B1 and B2.

Up until here, experimental data are consistent with the preconception that using a variable speed drive causes both added to the motor and added friction between the shaft and the bearings, resulting in higher temperatures of the latter.

Increased temperature difference in the pair of bearings is also not unexpected, being consistent with the usual rotodynamic of a shaft.

These observations are also valid for the high efficiency motor, for the trials with one inertia. For the trials with two inertias, there is an apparent inversion, and the one conducted using a variable speed drive shows slightly lower temperatures than the corresponding trial connecting directly to the grid.

This particular case, which will be for now treated as an exception, has to be looked into with more attention, though a possible explanation is a small rotating speed difference, caused by the fact that the variable speed drive does not receive feedback on the actual rotary speed of the shaft.

\section{Vibrational analysis}

As mentioned in the introduction, this paper presents a part of a broader study on the effects of power supply on the behaviour of an induction machine and its mechanical load, and a vibrational analysis was already performed in [2].

This time, for the sake of comparability, the results shown correspond to the same trial situations presented in the previous section. The vibrational behaviour is measured as presented in [1] and [2], with a pair of proximity sensors in quadrature, placed according to the caption in figure 2: (S1, S2) for the first inertia, and $(\mathrm{S} 3, \mathrm{~S} 4)$ for the second inertia.

Vibration amplitude is the Euclidean distance to the pair of sensors. The absolute value of the amplitude of vibration has no particular meaning in this context, and the significance can be found in the relative value as the frequency response is determined.

The vibration amplitude response to rotation frequency, measured in the first inertia (closest to the motor), for both motors with one and two inertias, is presented in figure 4:

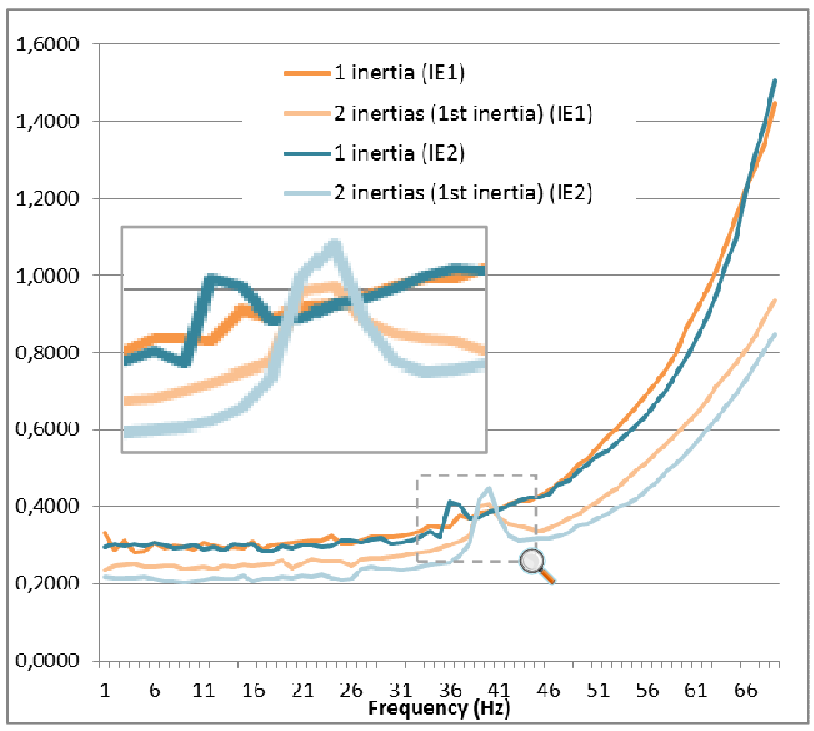

Fig. 4. A comparison of the vibration amplitude frequency response in four different trial platform configurations (fed through a VSD).

The careful observation of figure 4 provides some interesting insights to this question.

Firstly, the trials with two inertias present lower vibrational amplitude than those with one inertia, which can be explained by the added moment of inertia provided by the second inertia. Also, on any given curve, a small 'hill' around $36-41 \mathrm{~Hz}$ shows what may be a subharmonic resonance.

Now, the vibrational behaviour is mostly determined by the mechanical parameter ( 1 or 2 inertias) rather than the 
efficiency class of the motor: the effect of adding a second inertia is the damping of the vibrations, as well as moving the sub-harmonic resonance to a slightly higher frequency.

All of the former are rather expected results, thus confirmed. However, there is a not so expected observation: for the most of the curve, the trials with the IE2 motor present lower or equal vibration amplitude, with the exception of the neighbourhood of the sub-harmonic resonance; here, the vibration amplitude increases significantly, clearly surpassing that observed with the IE1 lower efficiency machine.

If this observation is to be found in other similar cases, this constitutes an added precaution to be taken when using IE2 or higher class machines.

\section{Conclusions and Outlook}

The work presented in this paper presents a few interesting questions and some preliminary answers to new situations posed by recent advances in technology.

A very first conclusion would be that, despite the widespread availability of ever more powerful simulation tools, experimental laboratory work is still of major importance in both validating assumed results and also providing interesting questions for exploratory research.

Also, the application of thermography to this study reveals its potential to the thermal analysis of such processes, with the advantages of being a non-intrusive measuring technique and also providing an easily readable visual representation of the results.

Thermal analysis through thermography, given the trial results example, be very useful in assisting the design, selection and preventive maintenance of the whole mechanical shaft, and especially the bearings, which are subjected to the highest amount of heat.

Questions on the derating of induction machines when driven by variable speed drives can also be posed, as they are in [3] and [4], since an increase in temperature was found to occur in most cases where this device was used.
On the vibrational analysis, an interesting point made is that the introduction of higher efficiency induction machines may reshuffle some of the present knowledge on vibrational behaviour, calling for further studies to be carried out in this particular subject. The former is more the case when European Directives and other international normative enforce that new motors sold have to be IE2 class or higher.

Unfortunately, due to physical limitations of the equipment, having to balance shaft flexibility with robustness and user safety when designing the trial platform, the main resonance frequency cannot be reached in any of the trials, leaving the question on how would the IE2 machine behave before this frequency.

\section{Acknowledgement}

The authors wish to acknowledge the financial support of Spanish government through "Ministerio de Ciencia e Innovación" and FEDER Funds. Research project ENE2007-6803-C04-01.

\section{References}

[1] J.P. Den Hartog, "Mechanical Vibrations", McGraw-Hill 4th ed. New York, 1956 (Reprint).

[2] F. Oliveira, M. P. Donsión, G. Peláez; "Rotating speed stability and mechanical vibrations analysis of a one-stage inertia flexible rotor driven by variable speed drives", Proceedings of International Conference on Renewable Energies and Power Quality (ICREPQ'09), Valencia (Spain), 2009

[3] Debruyne, C.; Desmet, J.; Derammelaere, S.; Vandevelde, L.; , "Derating factors for direct online induction machines when supplied with voltage harmonics: A critical view", in Proceedings of Electric Machines \& Drives Conference (IEMDC), Niagara Falls, Canada, IEEE International, May 2011. Print ISBN: 978-1-4577-0060-6.

[4] "Induction motors fed by PWM frequency inverters", WEG, 2009

[5] Ching-Yin Lee (et. al), "Effects of Voltage Harmonics on the Electrical and Mechanical Performance of a Three-phase Induction Motor", IEEE, 1998 